\title{
Randomized Clinical Trial of Periarticular Drug Injection used in combination Patient-Controlled Analgesia versus Patient-Controlled Analgesia Alone in Total Knee Arthroplasty
}

\author{
MN Sabran, MBBS, AJM Talha*, MS (Ortho), M Omar, MS (Ortho), MY Ibrahim*, MS (Ortho), \\ Y Shahril, MS (Ortho) \\ Department of Orthopaedic \& Traumatology, UKM Medical Centre, Kuala Lumpur, Malaysia \\ * Institute of Orthopaedic \& Traumatology, Hospital Kuala Lumpur, Kuala Lumpur, Malaysia
}

\begin{abstract}
This is a prospective randomized clinical trial to compare use of a combination of periarticular drug injection with patientcontrolled analgesia (PCA) to PCA alone in post-total knee arthroplasty (TKA). Thirty patients who were admitted for unilateral total knee arthroplasty were selected randomly into an Injection group or a Standard group. The periarticular injection contained Ropivacaine, Ketorolac and Adrenaline, given intra-operatively. The mean amount of opioid used was $22.87 \mathrm{mmol} / \mathrm{L}$ in the Injection group as compared to 39.78 $\mathrm{mmol} / \mathrm{L}$ in the Standard group $(\mathrm{p}=0.026)$. The Injection group had lower pain score at rest and during exercise ( $\mathrm{p}=0.021, \mathrm{p}=0.041$, respectively), as well as better return to function $(\mathrm{p}=0.026)$ and shorter hospital stay (6.1 days, Injection; 7.5 days, Standard, $\mathrm{p}=0.027$ ). Overall, the group receiving periarticular drugs injection had less pain, less narcotic usage, earlier return to function, similar experience of adverse effects and shorter hospital stays.
\end{abstract}

Key Words:

Total knee arthroplasty, periarticular drug injection, Ropivacaine, peri-operative analgesia.

\section{INTRODUCTION}

Pain following total knee arthroplasty (TKA) is a major problem, with approximately sixty percent of patients reporting severe pain while moderate pain is reported in approximately thirty percent of patients ${ }^{1}$. Generally, TKA patients receive either narcotic patient-controlled analgesia (PCA) or epidural analgesia. The most common side effects of narcotic usage are nausea and vomiting, which may discourage patients from early postoperative mobilization. Epidural analgesia, on the other hand, may be associated with epidural haematoma with concomitant thromboprophylaxis use. Motor block, another potential adverse effect of epidural analgesia may delay the onset of physiotherapy. Good pain control with minimal side effects allow for more effective post-operative rehabilitation.

Multimodal analgesic strategies are now the preferred protocol to reduce the occurrence of such side effects. Strategies such as intra-articular drug injection, continuous epidural, lumbar plexus and femoral and/or sciatic nerve blocks have resulted in improved in post-operative pain control and reduction in narcotic usage. However, these strategies are not without potential adverse effects such as epidural bleeding (when used with prophylactic anticoagulant therapy), diminished muscle control, urinary retention and nerve damage.

The objective of this study is to compare the combination of periarticular drug injection and PCA to PCA use alone in post TKA patients in terms of post-operative pain relief, total amount of PCA narcotic usage postoperatively, rate of return to normal function (as measured by the degree of active knee flexion and straight leg raising (SLR) tests during postoperative rehabilitation programme), the occurrence of side effects and complications and the length of hospital stay.

\section{MATERIALS AND METHODS}

This was a prospective, single-blinded, randomized controlled clinical trial on patients undergoing TKA. The study was carried out in the Orthopaedics wards, operation theatres, and follow-up clinics at Kuala Lumpur University Hospital. The study sample included all patients that were electively admitted to the orthopaedics ward for TKA surgery between October 2006 and July 2007. Inclusion criteria were: age between 45 and $75 \mathrm{y}$; weight between $50 \mathrm{~kg}$ and $100 \mathrm{~kg}$; ability to provide informed consent for and cooperate with the study; unilateral TKA. Exclusion criteria were: major psychological problems; previous drug dependency; allergies to ingredients of the injection or PCA;

Corresponding Author: Mohd Nazlee Sabran, Dept of Orthopaedics \& Traumatology, UKMMC, Jalan Yaacob Latif, Bandar Tun Razak, 56000, Cheras, Kuala Lumpur, Malaysia Email: dr nazlee@yahoo.com 
renal insufficiency; abnormal liver enzymes; history of stroke or major neurological deficit; uncontrolled angina; bilateral TKA; acute or chronic knee infection; and bifascicular cardiac block with a prolonged Q-T interval.

The sample size needed was estimated by calculating the standard difference (mean divided by the standard deviation) with reference to a previous study $(21.6 \mathrm{ml} / 25 \mathrm{ml}=0.86)^{1}$. With the sample power of 0.80 , the straight line was across number 45 on the normogram. Although, we calculated that the minimum sample size was 23 patients for each group (46 total), due to unavailability of the primary surgeons for continuation of the study, only 45 patients were recruited into this study during the 10 month recruitment period. Patients were divided into two groups (Standard Group receiving PCA = Group S; Injection Group receiving periarticular injection plus PCA = Group I) via simple random sampling. In order to minimize differences between the two groups due to other factors, the following protocol was followed. A standardized general anaesthesia was used for all patients and patients in both groups also received Celebrex $400 \mathrm{mg}$ and Paracetamol $1000 \mathrm{mg}$ QID, one day prior to the operation. All arthroplasties were performed using a midvastus arthrotomy with cord sparing technique performed by the two surgeons of the Joint Replacement Unit at Kuala Lumpur University hospital (who are directly involved in this study). Third, the periarticular injection was prepared by the anaesthetist and contained $100 \mathrm{ml}$ of $0.2 \%$ Ropivacaine (Naropin), mixed with $30 \mathrm{mg}$ of Ketorolac (Toradol) and 0.5 $\mathrm{ml}$ of Adrenaline (1:1000 dilution). Injections were given intra-operatively before the prosthesis implantation. Sixty $\mathrm{ml}$ was injected into the posterior capsule, medial collateral ligament \& lateral collateral ligament, and $40 \mathrm{ml}$ into the quadriceps, retinacular tissues, \& surrounding soft tissues. Postoperatively, all patients received intravenous PCA - 1.5 $\mathrm{mg}$ bolus of morphine (narcotic) with a lock out of five minutes, and a maximum of fifteen $\mathrm{mg} /$ hour for 48 hours. Oral analgesics (Celebrex $200 \mathrm{mg}$ Daily and Tablet Paracetamol 1000 mg QID) were continued until discharge. PCA opioid consumption given was measured at 6, 12, 24 and $48 \mathrm{~h}$ hours post-operatively and the end result was calculated as total opioid usage was calculated for each subject. Post-operative pain was scored using Visual Analogue Scale (VAS) three times a day until the PCA was taken off, usually by day two post-operation. The Visual Analogue Scale uses a scale from one to ten with one being no pain and ten being the most severe pain. Post-operative active knee flexion and straight leg raising were measured via goniometer on a daily basis Patients were observed for side effects of Ropivacaine (i.e., peri-oral paraesthesia, visual disturbances, hearing problems, dizziness, uncontrolled muscle contraction, convulsion, hypertension, bradycardia, or headache every fifteen minutes in the recovery room, and every four hours for $48 \mathrm{~h}$ postoperatively. Side effects of narcotics were also noted in the chart (i.e., nausea, vomiting, confusion, constipation, urinary retention, dizziness, sedation, respiratory depression or pruritus). Patient's criteria for discharge were VAS $\leq 2$, no signs of symptoms of surgical wound infection and adequate mobility around with or without aids.

This study was approved by the institutional ethics committee. Data analysis and interpretation of results were performed utilizing the SPSS software (version 12 for Windows). The Student t-test and chi-square were used to compare continuous and categorical variables, respectively between the two groups. Continuous variables are presented as a mean and standard deviation, and categorical variables are given as frequency and percentage. A value of $p=0.05$ was considered statistically significant.

\section{RESULTS}

Forty five patients were recruited into this study between October 2006 and July 2007, and 15 patients were excluded for various reasons. Six patients refused to give consent to take part in this study, another six patients had combined spinal-epidural anaesthesia for the surgery and continued with epidural anaesthesia postoperatively. Three patients had other indications for surgery; two patients had rheumatoid arthritis and one had osteoarthritis secondary to previous trauma (age, 45y). The mean length of hospital stay postsurgery was 6.1 days for the group I was significantly shorter than in the group $\mathrm{S}$ (mean, 7.5 days, $\mathrm{p}=0.027$ ).

Only 30 patients were available for data analysis ten months after surgery, 15 knees in 15 patients in group I, and 15 knees in 15 patients in group S. Demographic characteristics were comparable between the two groups (Table I).

\section{Pain Scores}

The Injection (I) group had a significantly lower mean VAS for pain at rest and during exercise than did Standard (S) group (14 patients with VAS $\leq 3$ at rest in group I, nine with VAS $\leq 3$ in group $S ; 12$ had VAS $\leq 3$ during exercise in group I, three had VAS $\leq 3$ during exercise in Group $S ; p=0.021$, $\mathrm{p}=0.041$, respectively) on the first postoperative day, as well as a significantly lower score for pain during exercise for the next forty eight hours after surgery (15 patient with VAS during exercise 3 in group I, eight with VAS $\leq 3$ during exercise for group $S ; p=0.011$ ). However, the VAS at rest and during exercise on the day of discharge was similar (Figure 1 \& 2) in both groups.

Patient-Controlled Analgesia Usage and Total Opioid Usage A PCA pump with morphine was maintained for more than $72 \mathrm{~h}$ for 11 patients in group $\mathrm{S}$ compared to only four patients in group I. Most patients in group I used the PCA machine less than forty eight hours and one patient in this group had the PCA for only twenty four hours. Five patients in Group I used less than $10.0 \mathrm{mmol} / \mathrm{L}$ of opioid via the PCA, and the maximum usage was less than $50.0 \mathrm{mmol} / \mathrm{L}$, while for 
Table I: Summary of demographic data and characteristics of patients

\begin{tabular}{|c|c|c|c|}
\hline Characteristics & & Group I $(n=15)$ & Group S $(n=15)$ \\
\hline Sex & $\begin{array}{l}\text { Female } \\
\text { Male }\end{array}$ & $\begin{array}{l}14 \\
1\end{array}$ & $\begin{array}{l}14 \\
1\end{array}$ \\
\hline Race & $\begin{array}{l}\text { Malay } \\
\text { Chinese } \\
\text { Indian }\end{array}$ & $\begin{array}{l}9 \\
3 \\
3\end{array}$ & $\begin{array}{l}8 \\
2 \\
5\end{array}$ \\
\hline Operative Side & $\begin{array}{l}\text { Right } \\
\text { Left }\end{array}$ & $\begin{array}{l}5 \\
10\end{array}$ & $\begin{array}{l}11 \\
4\end{array}$ \\
\hline Age & Mean (SD) year & $60(5)$ & $62(7)$ \\
\hline Weight & Mean (SD) kg & $72(11)$ & $68(9)$ \\
\hline Knee Score & Mean (SD) & $52(10)$ & $58(8)$ \\
\hline
\end{tabular}

$\mathrm{n}=$ numbers of patient

$\mathrm{SD}=$ Standard Deviation

Table Il: Summary of results

\begin{tabular}{|c|c|c|c|}
\hline Outcome & Group I & Group S & P-value \\
\hline $\begin{array}{l}\text { Pain Score, } \leq 3(\geq 4) \\
\text { POD1 - VAS at rest } \\
\text { VAS activity } \\
\text { POD2 - VAS at rest } \\
\text { VAS activity } \\
\text { POD3 - VAS at rest } \\
\text { VAS activity } \\
\text { On Discharge - VAS at rest } \\
\text { VAS activity }\end{array}$ & $\begin{array}{l}14(1) \\
12(3) \\
15(0) \\
15(0) \\
15(0) \\
15(0) \\
15(0) \\
15(0)\end{array}$ & $\begin{array}{l}9(6) \\
3(12) \\
14(1) \\
8(7) \\
14(1) \\
7(8) \\
15(0) \\
14(1)\end{array}$ & $\begin{array}{l}0.021 \\
0.041 \\
0.128 \\
0.011 \\
0.326 \\
0.018 \\
0.067 \\
0.008\end{array}$ \\
\hline $\begin{array}{l}\text { Opioid Consumption } \\
\text { Total, mL } \\
\text { No of days usage }\end{array}$ & $\begin{array}{c}22.87 \\
2\end{array}$ & $\begin{array}{c}39.78 \\
3\end{array}$ & $\begin{array}{l}0.026 \\
0.008\end{array}$ \\
\hline $\begin{array}{l}\text { Rehabilitation } \\
\text { POD3 - Knee Flexion, mean }{ }^{\circ} \\
\text { Straight Leg Raising, mean }{ }^{\circ} \\
\text { On Discharge - Knee Flexion, mean }{ }^{\circ} \\
\text { Straight Leg Raising, mean }{ }^{\circ} \\
\text { Nausea, n/N } \\
\text { Vomiting, n/N } \\
\text { Sedation, n/N } \\
\text { Dizziniess, n/N }\end{array}$ & $\begin{array}{l}75 \\
30 \\
90 \\
55 \\
4 / 15 \\
2 / 15 \\
1 / 15 \\
1 / 15\end{array}$ & $\begin{array}{c}45 \\
10 \\
80 \\
20 \\
5 / 15 \\
5 / 15 \\
5 / 15 \\
0 / 15\end{array}$ & $\begin{array}{l}0.027 \\
1.401 \\
0.023 \\
1.837 \\
0.162 \\
0.088 \\
0.088 \\
0.167\end{array}$ \\
\hline $\begin{array}{l}\text { Length Hospital Stay } \\
\text { No of Days Post-operatively, mean }\end{array}$ & 6.1 & 7.5 & 0.027 \\
\hline
\end{tabular}

Note:

- Abbreviation: VAS, Visual Analogue Scale, POD = Post Operation Day

- VAS $\leq 3$ is considered as satisfactory pain relief (patient can still sleep with the pain)

- VAS $>4$ is considered as less satisfactory pain relief (patient cannot sleep well)

- Group I = Injection group, Group S = Standard group

- $P$ value $\leq 0.05$ is considered statistically significant

patients in group $\mathrm{S}$, the lowest opioid usage was 12.0 $\mathrm{mmol} / \mathrm{L}$ and the maximum usage was $81.4 \mathrm{mmol} / \mathrm{L}$. Five patients in this group used more than $50.0 \mathrm{mmol} / \mathrm{L}$ of opioids (Figure 3). The average total opioid consumption was significantly lower in group I y $(22.87 \mathrm{mmol} / \mathrm{L}$ for Group I compared with $39.78 \mathrm{mmol} / \mathrm{L}$ for group $\mathrm{S} ; \mathrm{p}=0.026$ ).

\section{Return of Function}

The patients in group I showed better results than those in group $\mathrm{S}$ for the amount of active knee flexion on day three post-operation. All of them were able to flex their knee at least ninety degree without much pain $(p=0.023)$. There were four patients in the group $\mathrm{S}$ who did not get $90^{\circ}$ of knee flexion till the day they were discharged. However, the findings in the straight leg raising test showed no significant difference between the two groups. 


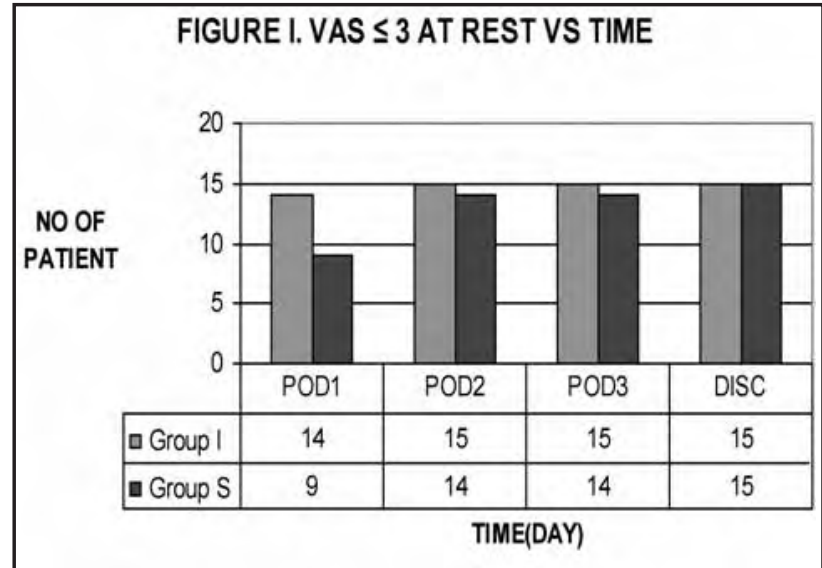

Fig. 1: Patients with VAS less than or equal to 3 at rest following surgery.

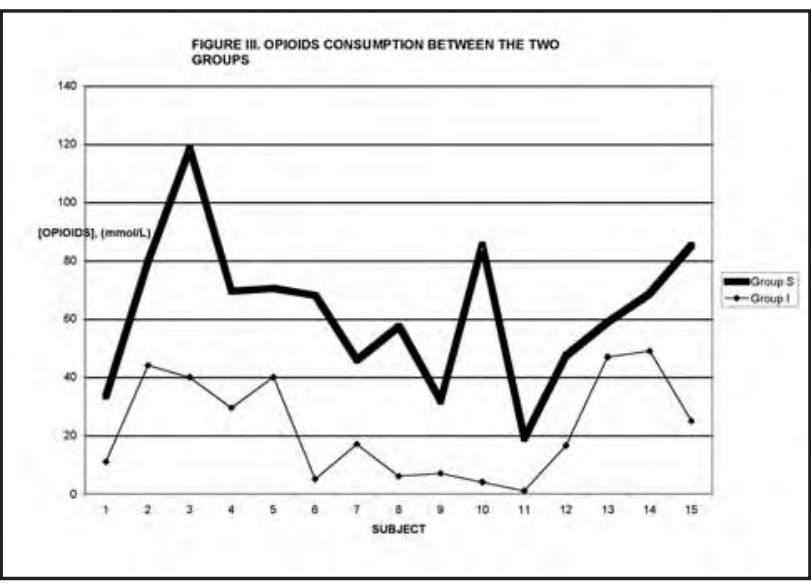

Fig. 3: Opioid consumption between the two groups.

\section{Side Effects of Pharmacotherapy}

Seven patients in the Injection group experience nausea vomiting and/or sedation while 15 had such symptoms in the Standard group, although not a statistically significant difference between the two groups. Dizziness was noted in only one patient (in the Injection group) for the entire study. (Figure 4). There were no other side effects of narcotics noted during the conduct of this study. Additionally, there were no complications related to the Ropivacaine infiltration reported. The infiltrated dose was generally higher than the manufacturer's recommended maximum dosage of $3 \mathrm{mg} / \mathrm{kg}$ (average, $2.8+/-0.6 \mathrm{mg} / \mathrm{kg}$; range, $2.2 \mathrm{mg} / \mathrm{kg}$ to $3.4 \mathrm{mg} / \mathrm{kg}$ ).

\section{DISCUSSION}

This study explored means by which surgeons can reduce pain and achieve a speedy recovery after TKA. Our findings are consistent with the results of two recent similar studies; both studies assessed periarticular infiltration with Ropivacaine, Ketorolac, and Adrenaline, although Busch et $a l^{2}$ added epimorphine to the solution and Vendittoli et $a l^{3}$ added a postoperative bolus through an intraarticular catheter. Whereas the positive results of these previous studies are not surprising, as the analgesic treatment in the

\section{FIGURE II. VAS $\leq 3$ DURING ACTIVITY VS TIME}

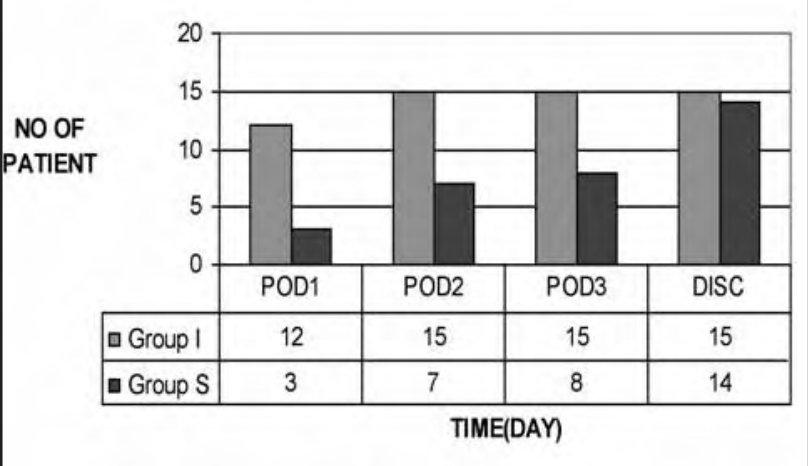

Fig. 2: Patients with VAS less than or equal to 3 during activity following surgery.

\section{FIGURE IV. OCCURRENCE OF DRUG SIDE EFFECTS}

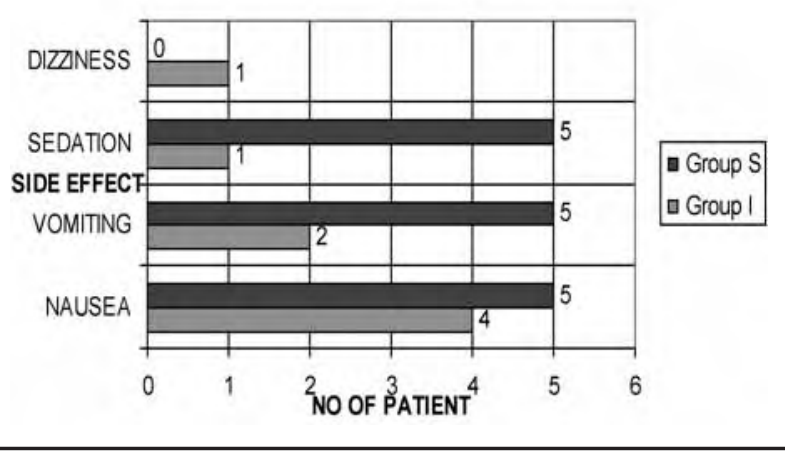

Fig. 4: Occurrence of drug side effects.

control groups mainly consisted of parenteral morphine, we chose to compare the periarticular treatment with the standard postoperative PCA (also parenteral morphine, but patient controlled).

The three active substances of the infiltration mixture used for this study were Ropivacaine, Ketorolac, and Adrenalin. Ropivacaine is pharmacologically similar to Bupivacaine but is associated with less cardiac and central nervous system toxicity, thus allowing patients to tolerate a larger dose ${ }^{4}$. The addition of epinephrine helps to reduce the toxicity of the local anaesthetic by slowing drug release into the circulation. The maximum tolerated doses of local anaesthetics with adrenaline administered periarticularly or by infiltration are not properly established ${ }^{5}$. Our patients received a dose of two hundred mg Ropivacaine injected into periarticular tissues. No patients reported tinnitus, tingling, peri-oral numbness, or other toxic symptoms of local anaesthetics. Several studies have shown that NSAIDs have a clinically relevant peripheral action, and that infiltration or injection provides better pain relief than intravenous administration ${ }^{5}$. To this end, we added Ketorolac to the periarticular solution. It is also established that peripheral opioid receptors are induced by inflammation ${ }^{6}$. 
Results demonstrated better pain control during the first $48 \mathrm{~h}$ post-operation for the Injection group patients, as reflected in the reduction of the mean total opioid consumption via the PCA machine in the Injection group as compared to the Standard group. Most patients in this study used the PCA machine for less than $48 \mathrm{~h}$. Although resting pain scores for TKA patients in both groups on the second postoperative day was not statistically different between the two groups, activity pain scores were significantly better in the Injection group. This allowed for (statistically significant) better physical therapy performance in Group I as measured by knee flexion; however, the findings in the straight leg raising test were not statistically significantly different between the two groups. Of note, the patients in Group I were able to perform the straight leg raising exercise at an earlier postoperative point in time than patients in Group I. Improved pain control and mobility allowed for a significant reduction in length of hospital stay in Group I over Group S. The possibility exists that the shortened length of stay in the Injection group patients could at least partially attributed to changes in patient expectations, as more emphasis was placed on early discharge for them. It is fair to say that this variable was not completely controlled for in our study.

We were able to demonstrate a subtle change in postoperative nausea and vomiting (PONV). More specifically, the number of patients experiencing nausea was similar in both groups but significantly fewer patients experienced vomiting in the Injection group, although no effort was made to grade the severity of these side effects. PONV is a multifactorial problem that, in this study, did have a modest correlation with total amount of opioid consumption.

The weaknesses in this study include the mall number of participating patients and the fact that only the patients were blinded for data variables assessment (study staff were aware of the group assignments). Some of the parameters may have had more significant differences if we were able to recruit more patients.

\section{CONCLUSION}

In conclusion, infiltration with Ropivacaine as part of the multimodal drug regime including standard postoperative PCA protocol demonstrated a good quality of analgesia after TKA, without increased risks. This study provides statistically significant findings in terms of pain score, early rehabilitation progress, fewer complications and shorter hospital stay, and also that the combination of peri-operative analgesia, post operative pain management and rapid mobilization may be effective in accelerating functional recovery from TKA. 


\section{REFERENCES}

1. Vendittoli PA, Makinen P, Drolet P, Lavigne M, Fallaha M, Guertin MC, Varin. A Multimodal Analgesia Protocol for Total Knee Arthroplasty, A Randomized, Controlled Study. J. Bone Joint Surg Am. 2006; 88: 282-9.

2. Bonica J. Postoperative pain. In: Bonica J, editor. The Management of Pain. 2nd Edition. Philadelphia: Lea and Febiger; 1990. pp. 461-80.

3. Busch CA, Shore BJ, Bhandri R, Ganapathy S, MacDonald SJ, Burne RB, Rorabeck CH, McCalden RW. Efficacy of Periarticular Multimodal Drug Injection in Total Knee Arthroplasty. A Randomized Trial. J. Bone Joint Surg. Am. 2006; 88: 59-963.

4. Mather LE, Copeland SE, and Ladd LA. Acute toxicity of local anesthetics: underlying pharmacokinetic and pharmacodynamic concepts. Reg. Anaesth Pain Med. 2005; 30(6): 553-566.

5. Rosenberg PH, Veering BT, and Urmey WF. Maximum recommended doses of local anesthetics: a multifactorial concept. Reg Anesth Pain Med. 2004; 29(6): 564-75.

6. Stein C, Schafer M, and Machelska H. Attacking pain at its source: new perspectives on opioid. Nat. Med. 2003; 9(8): 1003-8. 